\title{
Microsurgical Management of Complex Hypothalamic Hamartomas in the Era of Minimally Invasive Therapy: A Case Series and Narrative Review
}

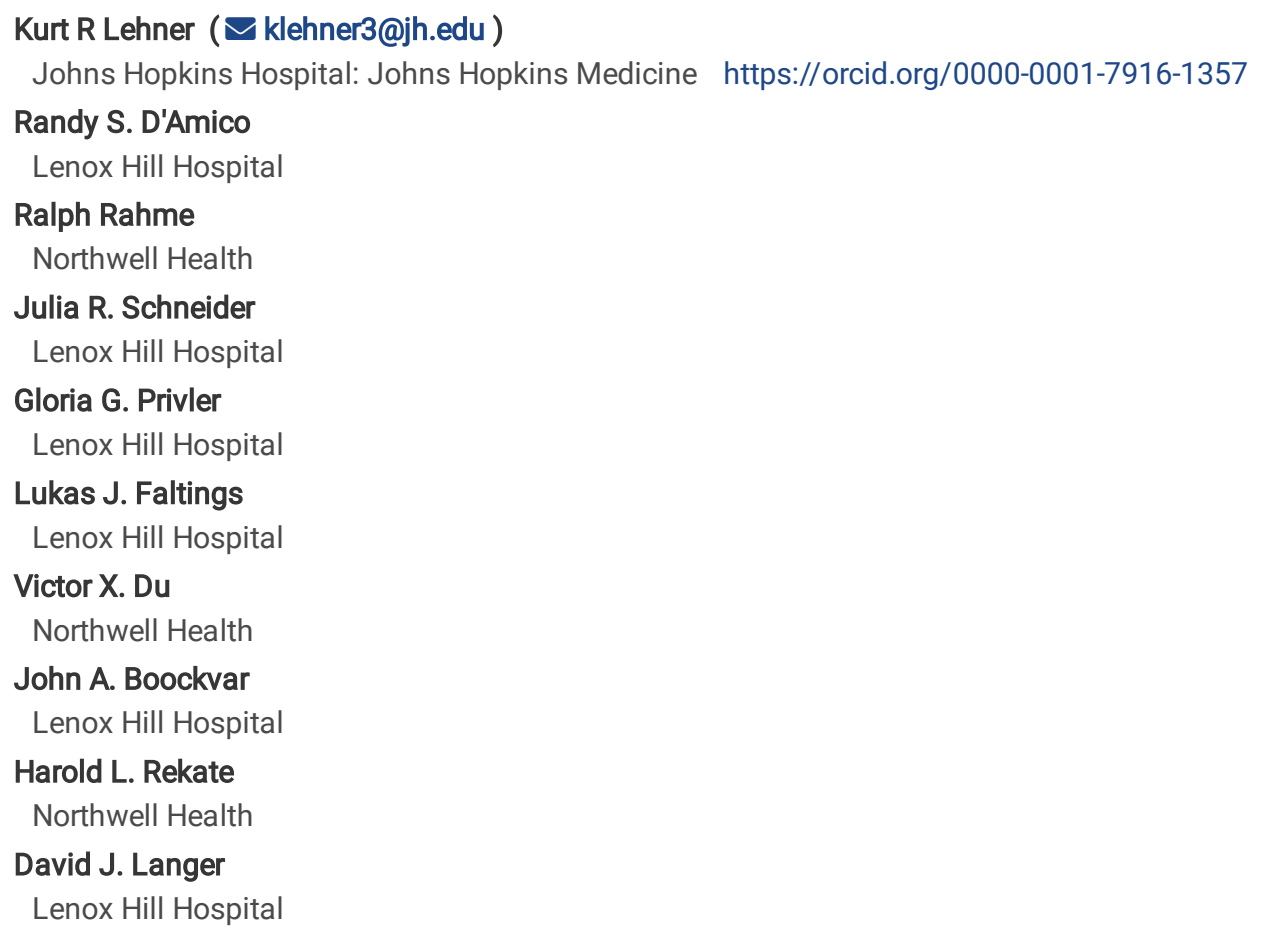

Research Article

Keywords: Hypothalamic Hamartomas, Invasive Therapy, Narrative

Posted Date: October 20th, 2021

DOI: https://doi.org/10.21203/rs.3.rs-947196/v1

License: (1) (1) This work is licensed under a Creative Commons Attribution 4.0 International License. Read Full License

Version of Record: A version of this preprint was published at World Neurosurgery on January 1st, 2022. See the published version at https://doi.org/10.1016/j.wneu.2022.01.031. 


\section{Abstract}

Introduction

Recently, there has been a paradigm shift in the management of hypothalamic hamartoma $(\mathrm{HH})$ from traditional microsurgical techniques to less invasive alternatives such as stereotactic radiosurgery and laser interstitial thermal therapy. However, large and extensive $\mathrm{HH}$ may fail to respond to minimally invasive therapies, ultimately necessitating microsurgery.

Methods

All patients who underwent microsurgical resection of a complex HH by the 2 senior authors (D.J.L., H.L.R.) in 2011-2017 were included. Charts were retrospectively reviewed and demographic, clinical, imaging, and outcome data were recorded.

Results

8 patients, 7 children and 1 adult, with a mean age of 7 years (10 months-27 years), were included. Of those, 2 had failed previous treatments. All 7 children presented with pharmacoresistant gelastic seizures and cognitive dysfunction, 6 exhibited central precocious puberty, and 3 had behavioral problems. Other seizure types affected 6/8 patients. Mean lesion size was $21.6 \mathrm{~mm}$ (14-31), all with interpeduncular extension and 5 with intraventricular extension (Delalande type I: 3, type III: 4, type IV: 1). A frontotemporal orbitozygomatic (FTOZ) approach with optic nerve decompression was used in all patients, supplemented by another approach in 3 (endoscopic transventricular: 3, transcallosal: 1). Gross total resection was achieved in 6 patients and subtotal resection in 2. Transient complications occurred in 3 patients (37.5\%): self-limited sodium imbalance $(n=3)$, subdural hygroma $(n=2)$. Permanent complications occurred in 2 patients $(25 \%)$ : perforator infarct ( $n=1)$, short-term memory loss $(n=1)$. All patients experienced seizure resolution postoperatively with preserved hypothalamic-pituitary axis function. After a mean follow-up of 41 months (2-66), 7 patients remain seizure-free, while 1 has rare recurrent seizures. Cognitive and behavioral symptoms improved significantly in all patients.

Conclusion

For large $\mathrm{HH}$ with interpeduncular extension, microsurgery via the FTOZ approach is a safe and highly effective treatment modality.

\section{Introduction}

Hypothalamic hamartomas $(\mathrm{HH})$ are benign lesions found in 1-2 per 100,000 persons. ${ }^{21,42}$ Clinically, HH presents with gelastic seizures and a catastrophic drug-resistant epilepsy with or without precocious puberty. ${ }^{37,25,38}$ Cognitive and behavioral disturbances including aggressive behavior and "rage attacks" are also observed in patients with $\mathrm{HH}^{12,42}$

Treatment of $\mathrm{HH}$ is surgical to disconnect or remove the $\mathrm{HH}$ from the normal brain. ${ }^{22}$ Minimally invasive approaches including laser interstitial thermal therapy (LITT) and stereotactic radiosurgery (SRS) are increasingly favored in treating HH. ${ }^{10,30,31}$ However, microsurgical approaches are still necessary for large lesions or those resistant to minimally invasive therapy. $1,17,22,24,7,23$

Frontotemporal-orbitozygomatic (FTOZ) craniotomies provide an approach to the anterior skull base with little retraction of the brain and excellent functional and cosmetic results. ${ }^{3,36}$ Here, we report our experience utilizing an FTOZ approach for resection of HH. We also provide a concise review of the literature comparing FTOZ resection of $\mathrm{HH}$ to other commonly used approaches to outline the role of FTOZ in management of hypothalamic hamartoma.

\section{Methods}

\section{Patients and clinical course}

A retrospective review was carried out on all patients undergoing resection of $\mathrm{HH}$ using an FTOZ craniotomy at our institution between January 2011 and December 2017. This included outpatient visits, operative reports, and review of MRI scans. All procedures and chart review were performed in accordance with local IRB approval.

\section{Literature search}

A PubMed literature search was conducted for relevant literature in English during the years 1990-2018. The terms "hypothalamic hamartoma", "surgery", "microsurgery", "laser interstitial thermal therapy", "LITT" "endoscopic", "radiosurgery", "radiofrequency", "gamma knife”, and "craniotomy" were used in various combinations for the search. The literature was reviewed and the relevant results regarding the following aspects: 1) Craniotomy for resection of $\mathrm{HH}$; 2) endoscopic resection of $\mathrm{HH}$; 3) LITT ablation of $\mathrm{HH}$; 4) radiosurgery for $\mathrm{HH}$. 


\section{Results}

\section{Clinical characteristics}

From 2011-2017 8 patients with HH underwent 9 hospital admissions for resection of HH with a FTOZ or combined approach (Table 1).

Seizure semiology was predominantly gelastic. 1 patient (patient 8) presented with CPS and generalized tonic-clonic (GTC) seizures. The duration of seizures prior to surgery at our institution ranged from 10 months to 11 years, the frequency of seizures ranged from $4-5$ seizures per week to greater than 100 episodes per day.

6 patients in our series showed signs of central precocious puberty (CPP). All pediatric patients showed signs of cognitive dysfunction or developmental delay at the time of surgery. 2 patients had received a diagnosis of attention-deficit hyperactivity disorder. 3 patients showed signs of inappropriate aggression with regular tantrums or rage attacks. 2 patients in our series had undergone prior surgical procedures for resection of $\mathrm{HH}$ at other institutions.

\section{Imaging findings}

MRI characteristics of hypothalamic hamartomas in our series are shown in Table 2. 5 patients had sessile type hamartomas with primarily vertical attachment to the hypothalamus. 3 patients had pedunculated hamartomas with a primarily horizontal attachment. All HH were nonenhancing and isointense to gray matter on T1W imaging and were either hyperintense or isointense on T2W imaging. The lesions occupied the suprasellar (SS) and interpeduncular (IP), and prepontine (PP) cisterns, five of which had an intraventricular (IV) component. Size of the lesions in the greatest dimension ranged from $10 \mathrm{~mm}$ to $31 \mathrm{~mm}$. Based on the Delalande and Fohlen classification system, 3 patients had class 1 HH's, 4 patients had class $3 \mathrm{HH}$ 's, and one patient had a class 4, or giant, $\mathrm{HH}$. Of note, concern for optic nerve compression was present in every patient's MRI.

\section{Surgical characteristics and complications}

Surgical technique for the FTOZ craniotomy and other approaches to a HH have been previously described..$^{3,22,40}$ All patients were consented for a possible two-stage procedure in the same hospital stay beginning with an FTOZ craniotomy followed by either a TAIF or endoscopic approach (Table 3). Significantly, the optic nerve was noted to be splayed intra-operatively in all patients and optic nerve decompression was performed allowing mobilization of the nerve to enlarge the optico-carotid triangle to facilitate resection. 5 patients underwent resection of HH utilizing an OZ craniotomy alone. 3 patients were treated with a combined approach. Length of stay (LOS) ranged from 5-21 days with an average LOS in patients undergoing a single procedure of 7.2 days and 11.5 days in patients undergoing a combined procedure. An endocrinologist managed the patients' post-operative endocrine care.

Patient 1 underwent an FTOZ craniotomy with an estimated 95\% resection. His post-operative course was complicated by hyponatremia and a subdural hygroma requiring a burr hole for drainage, delaying the second stage of his procedure by two months. Following resolution of the hygroma, he underwent endoscopic transventricular resection of the residual ipsilateral to the FTOZ craniotomy resulting in a GTR. Patients 4, 5, 6 , and 8 were treated with an FTOZ craniotomy ipsilateral to the HH's most extensive attachment. The course of the remaining patients is described below.

Complications relating to the surgical procedures included hyponatremia in two patients, transient diabetes insipidus (DI) in one patient, and a triphasic response in one patient leading to seizures. One patient developed a UTI. One patient was found to have a small thalamic stroke ipsilateral to the craniotomy resulting in long-term spasticity. Two patients developed subdural hygromas with one requiring surgical drainage. One patient developed short-term memory loss following his procedure.

\section{Outcomes}

Patient follow-up ranged from 2 months to 5 years. All patients experienced a decrease in seizure frequency following the final resection of HH. 6 patients experienced a 100\% decrease in seizures. In 2 patients (patient 3 and 4) who underwent subtotal resection of HH, 1 patient had initially decreased seizure frequency before gelastic seizures recurred. Patient 4 had a 100\% decrease in seizures until 3 years post-op when he developed rare recurrent gelastic seizures occurring 1-2 times per week. Patient 5 experienced a $100 \%$ decrease in gelastic seizures but had new complex partial seizures (CPS) occur 4 years post-operatively with MRI and electrographic findings consistent with mesial temporal lobe sclerosis (MTLS). All patients greater than 1-year post-op are no longer taking AEDs.

3 out of 4 patients receiving hormonal therapy for CPP no longer required treatment post-operatively. 2 patients (patients 1 and 2 ) experienced recurrent puberty; one required long-term medical therapy. No patients required treatment for permanent DI. 3 patients experienced increased appetite with significant weight gain post-op. Parents noted improved behavior and decreased rage attacks in all patients displaying signs of aggression pre-operatively. 


\section{Patient 2}

A 34-month-old boy presented with 1 year of infantile spasms, gelastic, and complex partial seizures and signs of precocious puberty. His parents reported temper tantrums. MRI revealed a $21 \times 14 \times 19 \mathrm{~mm}$ hypothalamic hamartoma (Figure $1 \mathrm{~A}$ ).

Due to the involvement of the interpeduncular cistern and the third ventricle as well as the size of the lesion and proximity to the optic nerve, the decision was made for a two-stage procedure for resection of the lesion. Stage one resection was carried out via a right-sided FTOZ craniotomy due to the predominance of the lesion on the right side. Intra-operatively, the ipsilateral optic nerve was noted to be splayed, and an optic nerve sheath fenestration and optic canal decompression was completed resulting in a significant decompression and allowing for mobilization of the nerve to enlarge the opticocarotid triangle through which the hamartoma was resected. An estimated 95\% resection was completed (Figure 1B). The post-op course was uneventful. Four days later, stage two resection was completed via an endoscopic TAIF approach resulting in GTR. The patient experienced transient DI in the post-operative period. At the most recent follow-up, the patient was seizure-free and on no AEDs. His parents reported improved temper tantrums and abnormally increased appetite.

\section{Patient 3}

A 13-month-old girl presented with 11 months of gelastic seizures occurring $>100$ times per day and language regression and concern for precocious puberty. MRI revealed a 27x31×22mm HH (Figure 2A). The patient's parents elected for surgical management.

Due to the size of the lesion with involvement of the third ventricle and the basal cisterns and proximity to the optic nerve, a two-stage approach was planned involving a skull base and transcallosal approach. The patient underwent a left-sided FTOZ craniotomy. As in patient 2 , the ipsilateral optic nerve was noted to be splayed, and an optic nerve decompression was completed. $90 \%$ resection was completed leaving the intraventricular portion of the $\mathrm{HH}$. 6 days later, the patient underwent a left-sided TAIF for resection of the residual resulting in $95 \%$ resection. The patient's post-operative course was complicated by transient hyponatremia and a urinary tract infection requiring antibiotics. The patient was started on an AED post-operatively. 1 month after the second stage of the operation, the patient developed recurrent severe dacrystic seizures. She returned to the OR approximately 2 months after the second stage of her initial operation for an endoscopic transcallosal resection of the residual resulting in an estimated $99 \%$ resection and complete disconnection of the $\mathrm{HH}$ (Figure 2B). At 9-month follow-up, the patient was seizure free, but was experiencing hyperphagia and weight gain. She had developed a small subdural hygroma which was managed conservatively.

\section{Patient 7}

A 12-year-old boy with a history of hypothalamic hamartoma status-post endoscopic-TAlF resection as a 2-year-old resulting in an estimated 80\% resection and LITT ablation as an 8-year-old at outside institutions presented with an estimated 300-500 gelastic seizures per day, most lasting less than 30 seconds. He had failed 4 AEDs, showed signs of precocious puberty controlled with hormonal therapy, displayed rage attacks, and had delayed speech acquisition and short-term memory loss. Physical exam revealed strabismus and blurry vision, the patient was otherwise intact. MRI demonstrated a 13×14×10mm hypothalamic hamartoma (Figure 3A). Based on the failure of comparatively less invasive approaches, the decision was made to proceed with resection of the lesion via an FTOZ craniotomy (Figure 3B). As above, the ipsilateral optic nerve was noted to be splayed, and an optic nerve decompression was completed. GTR was achieved. There were no peri-operative complications. At 6month follow-up, the patient was seizure free with significant hyperphagia and weight gain and little improvement in his aggression.

\section{Discussion}

As $\mathrm{HH}$ are intrinsically epileptogenic, definitive treatment requires complete disconnection or removal. While surgical resection was the mainstay of $\mathrm{HH}$ treatment for many years, newer, less invasive treatments have been developed and are increasingly preferred to traditional microsurgical treatment. In this study, we demonstrate the utility and safety of the FTOZ approach for the treatment of large and/or complex HH.

Surgery for HH was first reported in 1967 via a subfrontal approach; a report in 1969 described the removal of the temporal pole to access the $\mathrm{HH}^{25,26}$ In the late 1990 's, reports of the use of SRS appeared in the literature, representing a transition towards these minimally invasive techniques. ${ }^{14,28,29}$ Currently, the use of LITT is increasingly advocated due to short post-operative periods and minimal morbidity. ${ }^{10,43,44}$ The literature reviewed in the following sections is outlined in Table 4.

Stereotactic radiosurgery (SRS)

The first series of patients treated with SRS was published in $2000 .^{29}$ The same group has since conducted the only prospective trial examining the role of GKS in the treatment of $\mathrm{HH}^{30}$ In this study of 48 patients, the majority of $\mathrm{HH}$ were small (types I, II, or III). 19 of 48 patients experienced seizure freedom and an additional 14 experienced a worthwhile reduction in seizures; all had functional improvement with no permanent neurological or endocrinologic side effects. 7 (14.5\%) patients required microsurgery due to treatment failure. Similar results were seen in three separate studies. ${ }^{2,18,35}$ 
The International Stereotactic Radiosurgery Society released practice guidelines for the use of GKS in treatment of HH in 2017 providing level 2 evidence that that GKS has a better risk-benefit ratio for small hypothalamic hamartomas compared to surgical methods. ${ }^{19}$ Other studies have noted that neurological, cognitive, and social outcomes are improved with GKS which does not carry the same risk of poor memory outcomes and increased appetite seen with microsurgical methods. ${ }^{31,39}$ The studies agree that the drawbacks of GKS include delayed treatment effect (3 years are necessary to ascertain seizure outcome), lack of efficacy for large $\mathrm{HH}$, and the threat of damage to adjacent radiosensitive structures such as the optic chiasm.

\section{Radiofrequency ablation}

Radiofrequency ablation (RFA) is another minimally invasive approach to the treatment of HH which utilizes the conductive properties of an implanted depth electrode to thermally ablate tissue and disconnect the $\mathrm{HH}$ from normal parenchyma. ${ }^{14,28}$ Seizure freedom can frequently be achieved with the advantage of utilizing a depth electrode to record and locate the seizure-onset zone prior to RFA. ${ }^{13,41}$ Kameyama, et al, reported their experience with RFA utilizing 140 procedures in 100 patients with $\mathrm{HH}$ : $86 \%$ of patients treated reported freedom from gelastic seizures, $79 \%$ of patients reported freedom from other seizure types, and a total of $71 \%$ of patients reported complete seizure freedom. ${ }^{16}$ Post-operatively, transient neurological symptoms included short-term memory loss, hyperthermia, endocrine dysfunction, increased appetite, Horner's syndrome, supplementary motor area syndrome and emotional facial paresis. 2 cases of permanent pituitary dysfunction occurred in patients who received bilateral RFA for disconnection of $\mathrm{HH}$ with bilateral attachment. In general, RFA appears to be best suited for ablation of disconnection of small, sessile $\mathrm{HH}$. Treatment with RFA requires multiple trajectories and the authors warn against the use of bilateral RFA for disconnection to prevent endocrinologic complications.

\section{Laser Interstitial Thermal Therapy (LITT)}

LITT is a minimally invasive approach that accomplishes ablation of the seizure focus using an implanted laser catheter. ${ }^{32}$ Wilfong, et al, reported seizure freedom in 12 of 14 patients and no permanent neurologic or endocrinologic side effects. ${ }^{43}$ Another study reported similar outcomes with 6 of 7 patients reporting seizure freedom. ${ }^{10}$ Similarly, Xu, et al reported seizure freedom in $12 / 15$ patients with gelastic seizures and 5/9 with nongelastic seizures undergoing LITT treatment; $39 \%$ of patients experienced a transient neurological deficit with $22 \%$ of patients suffering persistent.$^{44}$ LITT treatment has resulted in a disabling amnestic syndrome in one patieint. ${ }^{45}$ LITT can be utilized for complete ablation or disconnection of the $\mathrm{HH}$, however, it may prove ill-suited for large $\mathrm{HH}$ with extended or bilateral connection to brain parenchyma, similar to RFA.

\section{Microsurgical resection}

Three approaches are utilized to treat HH microsurgically: endoscopic approaches, transcallosal approaches, and skull base approaches. Many advocate multi-stage operations for treatment of $\mathrm{HH}$.

Endoscopic transventricular resection can be utilized in the treatment of small $\mathrm{HH}$ with significant involvement of the third ventricle (type II or III). ${ }^{40,7,23,9}$ Smaller case series have also demonstrated the efficacy of endoscopic disconnection of smaller hypothalamic hamartomas. 8,11 The TAIF approach has also been advocated for $\mathrm{HH}$ with significant third-ventricular extension (Type 2). ${ }^{33,5,34,24}$ While the transcallosal approach is effective for the treatment of $\mathrm{HH}$, it has been associated with long term reduction in memory function. ${ }^{4}$

Pterional skull base approaches have yielded some success for treatment of hypothalamic hamartomas, however, access to the hypothalamus can be limited through this approach. ${ }^{11,27,15}$ Noteably, Drees, et al, reported a mean resection of $64 \%$ in 10 patients treated with transcallosal or endoscopic-pterional/endoscopic-FTOZ approaches; it was noted that giant HH led to significant difficulty in obtaining a complete resection. No patients experienced seizure freedom. 4 patients experienced persistent hormonal disturbances and 4 patients experienced hyperphagia and weight gain post-operatively; 2 patients experienced permanent neurological deficits, and 1 patient died immediately post-operatively. Based on these reports, large $\mathrm{HH}$ with broad attachments to the hypothalamus which are not amenable to minimally invasive approaches benefit from complete resection which may be limited in a pterional craniotomy.

The use of the FTOZ approach and variations has been discussed previously. ${ }^{20,36}$ This approach is advocated for treatment of pedunculated HH with interpeduncular extension and an inferior or horizontal plane of attachment to the hypothalamus by providing a wide exposure of the region of the $\mathrm{HH}$ with improvement in access to the superior aspect of the tumor with minimal frontal lobe retraction. Additionally, optic nerve decompression and mobilization can be carried out via this approach to aid in resection through the optico-carotid triangle creating a significantly larger surgical window. ${ }^{1}$

There is likely not a single ideal treatment for $\mathrm{HH}$. The Delalande and Fohlen classification system classifies $\mathrm{HH}$ into four groups based on lesion morphology (pedunculated or sessile), intraventricular location, horizontal or vertical attachment to the hypothalamus, and lesion size. ${ }^{11}$ Smaller lesions are amenable to SRS, and large lesions, including giant $\mathrm{HH}$, have been treated with RFT and LITT to with varying success. The utility of 
these approaches is limited by proximity of the $\mathrm{HH}$ to critical structures such as the optic apparatus. $\mathrm{HH}$ with significant $3^{\text {rd }}$ ventricular extension (Type 2 and 3) should be treated from above, preferably with an endoscopic approach which is thought to be less invasive than the TAIF approach with no known association to long-term memory disturbance. The TAIF approach is thought to be well suited for Type 2 lesions with simple attachment to the hypothalamus. Bilateral attachment to the hypothalamus, however, makes the endoscopic approach difficult from a single side, and if the lesion sits posteriorly over the mamillary bodies, great care must be taken to avoid damaging these structures lest devastating permanent memory disturbance occurs.

$\mathrm{HH}$ with significant extension into the basal cisterns and broad attachment to the inferior hypothalamus (Type $1,3,4)$ that are not amenable to SRS, RFA, or LITT create a favorable situation for skull base approaches. Compared to a pterional approach, the FTOZ approach provides a wide working corridor and our review of the literature and case series indicates a higher rate of gross total or near gross total resection when used alone or in combination. In treatment of complex $\mathrm{HHs}$ with intraventricular and interpeduncular components with unilateral or bilateral attachment to the hypothalamus, or a HH that has failed treatment with LITT, SRS, or another approach, a combination of transventricular and skull base approaches may be needed for adequate treatment of the lesion.

\section{Conclusion}

For large $\mathrm{HH}$ with complex attachment to the hypothalamus and proximity to other neural structures, microsurgery via the FTOZ approach is a safe and highly effective treatment modality. As surgical success requires the complete disconnection or removal of the $\mathrm{HH}$, additional treatment with other approaches or modalities may be required for adequate treatment.

\section{Declarations}

Compliance with Ethical Standards: This study was approved by the IRB at Northwell Health.

Consent to participate: Informed consent was obtained from all individuals participating in this study.

Conflicts of interest: The authors have no relevant conflicts of interest to report.

Funding: The authors did not receive support from any organization for the submitted work. The authors have no relevant financial or nonfinancial interests to disclose.

Author contributions: Project was conceived and designed by David Langer, Harold Rekate, and Kurt Lehner. Manuscript was prepared by Kurt Lehner and data acquisition was completed by Kurt Lehner, Ralph Rahme, Julia Schneider, Lukas Faltings, and Gloria Privler. All authors reviewed the manuscript, revised it critically, and approved of publication. All authors agree to be accountable for all aspects of the work in ensuring that questions related to the accuracy or integrity of any part of the work are appropriately investigated and resolved.

Data availability. The datasets generated during and/or analysed during the current study are available from the corresponding author on reasonable request.

\section{References}

1. Abla AA, Rekate HL, Wilson DA, Wait SD, Uschold TD, Prenger E, et al: Orbitozygomatic resection for hypothalamic hamartoma and epilepsy: patient selection and outcome. Child's Nervous System 27:265-277, 2011

2. Abla AA, Shetter AG, Chang SW, Wait SD, Brachman DG, Ng YT, et al: Gamma Knife surgery for hypothalamic hamartomas and epilepsy: patient selection and outcomes. J Neurosurg 113 Suppl:207-214, 2010

3. Al-Mefty O: Supraorbital-pterional approach to skull base lesions. Neurosurgery 21:474-477, 1987

4. Anderson JF, Rosenfeld JV: Long-term cognitive outcome after transcallosal resection of hypothalamic hamartoma in older adolescents and adults with gelastic seizures. Epilepsy Behav 18:81-87, 2010

5. Andrew M, Parr JR, Stacey R, Rosenfeld JV, Hart Y, Pretorius P, et al: Transcallosal resection of hypothalamic hamartoma for gelastic epilepsy. Childs Nerv Syst 24:275-279, 2008

6. Brandmeir N, Acharya V, Sather M: Robot Assisted Stereotactic Laser Ablation for a Radiosurgery Resistant Hypothalamic Hamartoma. Cureus 8:e581, 2016

7. Chibbaro S, Cebula H, Scholly J, Todeschi J, Ollivier I, Timofeev A, et al: Pure endoscopic management of epileptogenic hypothalamic hamartomas. Neurosurgical Review:1-7, 2017 
8. Choi JU, Yang KH, Kim TG, Chang JH, Chang JW, Lee BI, et al: Endoscopic disconnection for hypothalamic hamartoma with intractable seizure. Report of four cases. J Neurosurg 100:506-511, 2004

9. Drees C, Chapman K, Prenger E, Baxter L, Maganti R, Rekate H, et al: Seizure outcome and complications following hypothalamic hamartoma treatment in adults: endoscopic, open, and Gamma Knife procedures. J Neurosurg 117:255-261, 2012

10. Du VX, Gandhi SV, Rekate HL, Mehta AD: Laser interstitial thermal therapy: A first line treatment for seizures due to hypothalamic hamartoma? Epilepsia 58:77-84, 2017

11. Fohlen M, Lellouch A, Delalande O: Hypothalamic hamartoma with refractory epilepsy: surgical procedures and results in 18 patients. Epileptic disorders 5:267-273, 2003

12. Frattali C, Liow K, Craig G, Korenman L, Makhlouf F, Sato S, et al: Cognitive deficits in children with gelastic seizures and hypothalamic hamartoma. Neurology 57:43-46, 2001

13. Fujimoto Y, Kato A, Saitoh Y, Ninomiya H, Imai K, Sakakibara RI, et al: Stereotactic radiofrequency ablation for sessile hypothalamic hamartoma with an image fusion technique. Acta Neurochir (Wien) 145:697-700; discussion 700-691, 2003

14. Fukuda M, Kameyama S, Wachi M, Tanaka R: Stereotaxy for hypothalamic hamartoma with intractable gelastic seizures: technical case report. Neurosurgery 44:1347-1350, 1999

15. Jayalakshmi S, Panigrahi M, Reddy R, Somayajula S: Clinical characteristics and long-term outcome of surgery for hypothalamic hamartoma in children with refractory epilepsy. Ann Indian Acad Neurol 17:43-47, 2014

16. Kameyama S, Shirozu H, Masuda H, Ito Y, Sonoda M, Akazawa K: MRI-guided stereotactic radiofrequency thermocoagulation for 100 hypothalamic hamartomas. J Neurosurg 124:1503-1512, 2016

17. Machado HR, Hoffman HJ, Hwang PA: Gelastic seizures treated by resection of a hypothalamic hamartoma. Child's Nervous System 7:462-465, 1991

18. Mathieu D, Deacon C, Pinard CA, Kenny B, Duval J: Gamma Knife surgery for hypothalamic hamartomas causing refractory epilepsy: preliminary results from a prospective observational study. J Neurosurg 113 Suppl:215-221, 2010

19. McGonigal A, Sahgal A, De Salles A, Hayashi M, Levivier M, Ma L, et al: Radiosurgery for epilepsy: Systematic review and International Stereotactic Radiosurgery Society (ISRS) practice guideline. Epilepsy Res 137:123-131, 2017

20. Miranda P, Esparza J, Cabrera A, Hinojosa J: Giant hypothalamic hamartoma operated through subfrontal approach with orbitary rim osteotomy. Pediatr Neurosurg 42:254-257, 2006

21. Mittal S, Mittal M, Montes JL, Farmer JP, Andermann F: Hypothalamic hamartomas. Part 1. Clinical, neuroimaging, and neurophysiological characteristics. Neurosurg Focus 34:E6, 2013

22. Mittal S, Mittal M, Montes JL, Farmer JP, Andermann F: Hypothalamic hamartomas. Part 2. Surgical considerations and outcome. Neurosurg Focus 34:E7, 2013

23. Ng Y-T, Rekate H, Prenger E, Wang N, Chung S, Feiz-Erfan I, et al: Endoscopic resection of hypothalamic hamartomas for refractory symptomatic epilepsy. Neurology 70:1543-1548, 2008

24. Ng Yt, Rekate HL, Prenger EC, Chung SS, Feiz-Erfan I, Wang NC, et al: Transcallosal resection of hypothalamic hamartoma for intractable epilepsy. Epilepsia 47:1192-1202, 2006

25. Northfield D, Russell D: Pubertas praecox due to hypothalamic hamartoma: report of two cases surviving surgical removal of the tumour. Journal of neurology, neurosurgery, and psychiatry 30:166, 1967

26. Paillas J, Roger J, Toga M, Soulayrol R, Salamon G, Dravet C, et al: Hamartoma of the hypothalamus. Clinical, radiological and histological study. Results of excision. Revue neurologique 120:177, 1969

27. Palmini A, Chandler C, Andermann F, Da Costa JC, Paglioli-Neto E, Polkey C, et al: Resection of the lesion in patients with hypothalamic hamartomas and catastrophic epilepsy. Neurology 58:1338-1347, 2002

28. Parrent AG: Stereotactic radiofrequency ablation for the treatment of gelastic seizures associated with hypothalamic hamartoma. Case report. J Neurosurg 91:881-884, 1999

Page $7 / 14$ 
29. Regis J, Bartolomei F, de Toffol B, Genton P, Kobayashi T, Mori Y, et al: Gamma knife surgery for epilepsy related to hypothalamic hamartomas. Neurosurgery 47:1343-1351; discussion 1351-1342, 2000

30. Régis J, Lagmari M, Carron R, Hayashi M, McGonigal A, Daquin G, et al: Safety and efficacy of Gamma Knife radiosurgery in hypothalamic hamartomas with severe epilepsies: A prospective trial in 48 patients and review of the literature. Epilepsia 58:60-71, 2017

31. Régis J, Scavarda D, Tamura M, Nagayi M, Villeneuve N, Bartolomei F, et al: Epilepsy related to hypothalamic hamartomas: surgical management with special reference to gamma knife surgery. Child's Nervous System 22:881-895, 2006

32. Rolston JD, Chang EF: Stereotactic Laser Ablation for Hypothalamic Hamartoma. Neurosurg Clin N Am 27:59-67, 2016

33. Rosenfeld JV, Harvey AS, Wrennall J, Zacharin M, Berkovic SF: Transcallosal resection of hypothalamic hamartomas, with control of seizures, in children with gelastic epilepsy. Neurosurgery 48:108-118, 2001

34. Roth J, Bercu MM, Constantini S: Combined open microsurgical and endoscopic resection of hypothalamic hamartomas. J Neurosurg Pediatr 11:491-494, 2013

35. Selch MT, Gorgulho A, Mattozo C, Solberg TD, Cabatan-Awang C, DeSalles AA: Linear accelerator stereotactic radiosurgery for the treatment of gelastic seizures due to hypothalamic hamartoma. Minim Invasive Neurosurg 48:310-314, 2005

36. Siomin V, Spektor S, Beni-Adani L, Constantini S: Application of the orbito-cranial approach in pediatric neurosurgery. Child's Nervous System 17:612-617, 2001

37. Striano S, Striano P, Sarappa C, Boccella P: The clinical spectrum and natural history of gelastic epilepsy-hypothalamic hamartoma syndrome. Seizure 14:232-239, 2005

38. Takeuchi J, Handa H: Pubertas praecox and hypothalamic hamartoma. Neurosurgical review 8:225-231, 1985

39. Wagner K, Buschmann F, Zentner J, Trippel M, Schulze-Bonhage A: Memory outcome one year after stereotactic interstitial radiosurgery in patients with epilepsy due to hypothalamic hamartomas. Epilepsy Behav 37:204-209, 2014

40. Wait SD, Abla AA, Killory BD, Nakaji P, Rekate HL: Surgical approaches to hypothalamic hamartomas. Neurosurg Focus 30:E2, 2011

41. Wang W, Wang W, Guo X, Zeng Y, Jiang X: Hypothalamic hamartoma causing gelastic seizures treated with stereotactic radiofrequency thermocoagulation. Epileptic Disord 11:333-338, 2009

42. Weissenberger AA, Dell ML, Liow K, Theodore W, Frattali CM, Hernandez D, et al: Aggression and psychiatric comorbidity in children with hypothalamic hamartomas and their unaffected siblings. J Am Acad Child Adolesc Psychiatry 40:696-703, 2001

43. Wilfong AA, Curry DJ: Hypothalamic hamartomas: optimal approach to clinical evaluation and diagnosis. Epilepsia 54 Suppl 9:109-114, 2013

44. Xu DS, Chen T, Hlubek RJ, Bristol RE, Smith KA, Ponce FA, et al: Magnetic Resonance Imaging-Guided Laser Interstitial Thermal Therapy for the Treatment of Hypothalamic Hamartomas: A Retrospective Review. Neurosurgery, 2018

45. Zubkov S, Del Bene VA, MacAllister WS, Shepherd TM, Devinsky O: Disabling amnestic syndrome following stereotactic laser ablation of a hypothalamic hamartoma in a patient with a prior temporal lobectomy. Epilepsy Behav Case Rep 4:60-62, 2015

\section{Tables}

Table 1: Pre-operative characteristics of patients with complex hypothalamic hamartomas defined as having significant intraventricular and interpeduncular extension or as undergoing a re-operation. 


\begin{tabular}{|c|c|c|c|c|c|c|c|c|c|c|c|}
\hline $\mathrm{Pt}$ & Age & Sex & Seizures & $\begin{array}{l}\text { Seizure } \\
\text { duration }\end{array}$ & $\begin{array}{l}\text { Seizure } \\
\text { Frequency }\end{array}$ & $\begin{array}{l}\text { AED } \\
\text { trials }\end{array}$ & CPP & $\begin{array}{l}\text { Endocrine } \\
\text { treatment }\end{array}$ & $\begin{array}{l}\text { Cognitive } \\
\text { dysfunction }\end{array}$ & $\begin{array}{l}\text { Behavior } \\
\text { issues }\end{array}$ & $\begin{array}{l}\text { Prior } \\
\text { Surgery }\end{array}$ \\
\hline 1 & $\begin{array}{l}18 \mathrm{mo} \\
20 \mathrm{mo}\end{array}$ & M & $\begin{array}{l}\text { Gelastic, } \\
\text { absence }\end{array}$ & $11 \mathrm{mo}$ & $>100 / d$ & 1 & $\mathrm{Y}$ & Lupron & Speech delay & $\mathrm{N}$ & N; FTOZ \\
\hline 2 & $34 \mathrm{mo}$ & $M$ & $\begin{array}{l}\text { Gelastic, } \\
\text { spasms }\end{array}$ & $1 y$ & $6 / d$ & 0 & Y & $\begin{array}{l}\text { Lupron; } \\
\text { supprelin }\end{array}$ & Speech delay & Tantrums & $\mathrm{N}$ \\
\hline 3 & $13 \mathrm{mo}$ & $\mathrm{F}$ & Gelastic & $11 \mathrm{mo}$ & $>100 / d$ & 0 & $\mathrm{Y}$ & None & $\begin{array}{l}\text { Gross motor } \\
\text { and speech } \\
\text { delay }\end{array}$ & $\mathrm{N}$ & $\mathrm{N}$ \\
\hline 4 & $8 y$ & M & $\begin{array}{l}\text { Gelastic, } \\
\text { CPS }\end{array}$ & $7 y$ & $10-12 / d$ & 3 & $\mathrm{~N}$ & None & $\begin{array}{l}\text { Learning } \\
\text { difficulty }\end{array}$ & $\begin{array}{l}\text { Tantrums/rage } \\
\text { attacks }\end{array}$ & $\mathrm{N}$ \\
\hline 5 & $10 \mathrm{mo}$ & M & $\begin{array}{l}\text { Gelastic, } \\
\text { CPS, SG }\end{array}$ & $10 \mathrm{mo}$ & $>100 / d$ & 3 & Y & Lupron & Gross Motor & $\mathrm{N}$ & TAIF; VPS \\
\hline 6 & $3 y$ & $M$ & $\begin{array}{l}\text { Gelastic, } \\
\text { CPS }\end{array}$ & $17 \mathrm{mo}$ & $5-10 / d$ & 2 & Y & None & Poor attention & $\mathrm{N}$ & $\mathrm{N}$ \\
\hline 7 & $12 y$ & $M$ & Gelastic & $11 y$ & $2-3 / d$ & 2 & Y & Lupron & $\begin{array}{l}\text { Speech delay, } \\
\text { STM, ADHD }\end{array}$ & Rage attacks & $\begin{array}{l}\text { Endoscopic; } \\
\text { LITT }\end{array}$ \\
\hline 8 & $27 y$ & $M$ & $\begin{array}{l}\text { CPS; } \\
\text { GTC }\end{array}$ & $11 \mathrm{mo}$ & $4-5 / w$ & 2 & $\mathrm{~N}$ & None & None & None & None \\
\hline
\end{tabular}

Table 2: Pre-operative imaging characteristics of patients with complex HH. Class is Delalande and Fohlen classification. S: sessile; $P$ : pedunculated; SS: suprasellar; IP: Interpeduncular; PP: prepontine; IV: Intraventricular; Iso: isointense to gray matter; Hyper: hyperintense to gray matter; Enh: enhancement; DS: dorsum sellae; VPS: Ventriculo-peritoneal shunt.

\begin{tabular}{|llllllllll|}
\hline Pt & Class & Type & Size $(\mathrm{mm})$ & Cisterns & IV? & T1 & T2 & Enh & Other \\
\hline 1 & 3 & S & $23 \times 25 \times 24$ & SS, IP & Y & Iso & Hyper & No & Remodeling of DS \\
2 & 3 & S & $18 \times 20 \times 20$ & SS, IP & Y & Iso & Hyper & No & Remodeling of DS \\
\hline 3 & 4 & S & $27 \times 31 \times 22$ & SS, IP & Y & Iso & Iso & No & Remodeling of DS \\
\hline 4 & 3 & S & $13 \times 15 \times 14$ & SS, IP & Y & Iso & Hyper & No & Remodeling of DS \\
\hline 5 & 3 & S & $23 \times 20 \times 18$ & SS, IP & Y & Iso & Iso & No & Prior surgical changes, VPS, Remodeling of DS \\
\hline 6 & 1 & P & $19 \times 16 \times 20$ & SS, IP & N & Iso & Hyper & No & None \\
\hline 7 & 1 & P & $13 \times 14 \times 10$ & SS, IP & N & Iso & Hyper & No & Prior surgical changes, Remodeling of DS \\
\hline 8 & 1 & P & $22 \times 25 \times 16$ & IP, PP & N & Iso & Hyper & No & Chiari 1; Remodeling of DS \\
\hline
\end{tabular}

Table 3: Surgical characteristics and outcomes of orbitozygomatic (OZ) or combined approaches to hypothalamic hamartomas. EBL: estimated blood loss; LOS: length of stay; FU: follow-up; sz: seizure; AEDs: anti-epileptic drugs; Endo: endoscopic intraventricular; TAIC: transcallosal, anterior-interforniceal; GTR: gross total resection; min: minimal; SD: subdural; UTI: urinary tract infection; DI: diabetes insipidus; STM: short-term memory loss. ${ }^{\star} P t 1$ underwent two surgeries, $R$ OZ and $R$ Endo. Outcomes from each procedure are separated by a semi-colon. ${ }^{\star} * 100 \%$ reduction before gelastic seizure recurrence $3 y$ post-op. ${ }^{\star *} 4 y$ post-op patient experiencing CPS and electrophysiologic and MRI findings consistent with mesial temporal lobe sclerosis. 


\begin{tabular}{|c|c|c|c|c|c|c|c|c|c|c|c|}
\hline $\mathrm{Pt}$ & Approach & $\begin{array}{l}\% \\
\text { Resection }\end{array}$ & $\begin{array}{l}\mathrm{EBL} \\
\text { (cc) }\end{array}$ & $\begin{array}{l}\text { LOS } \\
\text { (days) }\end{array}$ & $\begin{array}{l}\text { Early } \\
\text { complications }\end{array}$ & FU & $\begin{array}{l}\% \text { Sz } \\
\text { decrease }\end{array}$ & AEDs & Endocrine & $\begin{array}{l}\text { Behavior } \\
\text { change }\end{array}$ & $\begin{array}{l}\text { Late } \\
\text { complications }\end{array}$ \\
\hline 1 * & $\begin{array}{l}\text { R FTOZ; } \\
\text { R Endo }\end{array}$ & 95\%; GTR & $\begin{array}{l}50 ; \\
\min \end{array}$ & $7 ; 3$ & $\begin{array}{l}\text { Hyponatremia, } \\
\text { SD hygroma }\end{array}$ & $4 y$ & $100 \%$ & 0 & Supprelin & Hyperphagia & None \\
\hline 2 & $\begin{array}{l}\text { R FTOZ, } \\
\text { L Endo }\end{array}$ & 95\%; GTR & $\begin{array}{l}100 \\
\min \end{array}$ & 11 & Transient DI & $5 y$ & $100 \%$ & 0 & $\begin{array}{l}\text { Recurring } \\
\text { puberty } \\
(7 y)\end{array}$ & $\begin{array}{l}\text { Hyperphagia, } \\
\text { resolved } \\
\text { aggression }\end{array}$ & None \\
\hline 3 & $\begin{array}{l}\text { L FTOZ, } \\
\text { L TAIF; R } \\
\text { endo }\end{array}$ & $\begin{array}{l}90 \% ; \\
95 \% ; 99 \%\end{array}$ & $\begin{array}{l}100 \\
150 \\
\min \end{array}$ & $12 ; 5$ & $\begin{array}{l}\text { Hyponatremia, } \\
\text { UTI }\end{array}$ & $9 \mathrm{mo}$ & $100 \%$ & 1 & None & Hyperphagia & $\begin{array}{l}\text { Transient } \\
\text { dacrystic sz, } \\
\text { SD Hygroma }\end{array}$ \\
\hline 4 & R FTOZ & $95 \%$ & 50 & 5 & None & $4 y$ & $90 \% * \star$ & 0 & None & $\begin{array}{l}\text { Improved } \\
\text { aggression }\end{array}$ & None \\
\hline 5 & R FTOZ & GTR & 150 & 21 & $\begin{array}{l}\text { Triphasic, sz, } \\
\mathrm{R} \text { thalamic } \\
\text { stroke }\end{array}$ & $4 y$ & 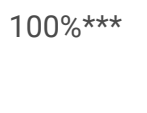 & 0 & None & None & Spasticity \\
\hline 6 & L FTOZ & GTR & 100 & 5 & None & $6 \mathrm{mo}$ & $100 \%$ & 1 & None & $\begin{array}{l}\text { Improved } \\
\text { aggression }\end{array}$ & None \\
\hline 7 & R FTOZ & GTR & 50 & 7 & None & $6 \mathrm{mo}$ & $100 \%$ & 2 & None & $\begin{array}{l}\text { Hyperphagia, } \\
\text { aggression } \\
\text { unchanged }\end{array}$ & None \\
\hline 8 & R FTOZ & GTR & 200 & 12 & None & $1.5 y$ & $100 \%$ & 0 & None & None & STM \\
\hline
\end{tabular}

Table 4: A summary of relevant studies examining the treatment of hypothalamic hamartoma. *All patients in this series had a subtotal resection of the $\mathrm{HH}$, hence the low incidence of seizure freedom in these patients. 


\begin{tabular}{|c|c|c|c|c|c|c|}
\hline Series & Surgical Approach & Subjects & $\begin{array}{l}\text { Seizure } \\
\text { freedom } \\
(\%)\end{array}$ & $\begin{array}{l}\text { Worthwhile } \\
\text { improvement in } \\
\text { seizures (\%) }\end{array}$ & $\begin{array}{l}\text { Permanent } \\
\text { Neurological } \\
\text { Complications } \\
(\%)\end{array}$ & $\begin{array}{l}\text { Permanent } \\
\text { endocrinologic } \\
\text { complications (\%) }\end{array}$ \\
\hline $\begin{array}{l}\text { Chibbaro, et } \\
\mathrm{al}^{7}\end{array}$ & Endoscopic & 14 & $8(57)$ & $2(14)$ & 0 & 0 \\
\hline $\begin{array}{l}\text { Fohlen, et } \\
\mathrm{al}^{11}\end{array}$ & Endoscopic & 3 & $2(67)$ & $1(33)$ & 0 & 0 \\
\hline Drees, et al ${ }^{9}$ & Endoscopic & 22 & $8(36)$ & $14(67)$ & $1(5)$ & Hyperphagia (59) \\
\hline $\mathrm{Ng}$, et $\mathrm{al}^{23}$ & Endoscopic & 37 & $18(49)$ & $8(22)$ & STM (8) & 0 \\
\hline Choi, et $\mathrm{al}^{8}$ & Endoscopic & 4 & $2(50)$ & 0 & 0 & 0 \\
\hline $\begin{array}{l}\text { Rosenfeld, et } \\
\mathrm{al}^{33}\end{array}$ & TAIF & 5 & $3(60)$ & $2(40)$ & 0 & Hyperphagia (40) \\
\hline $\begin{array}{l}\text { Andrew, et } \\
\mathrm{al}^{5}\end{array}$ & TAIF & 5 & $1(20)$ & $4(80)$ & 0 & 0 \\
\hline $\mathrm{Ng}$, et $\mathrm{al}^{24}$ & TAIF & 26 & $14(54)$ & $9(41)$ & STM (8) & $\begin{array}{l}\text { Panhypopituitarism } \\
\text { (8) }\end{array}$ \\
\hline Roth, et al ${ }^{34}$ & TAIF/Endoscopic & 2 & $2(100)$ & 0 & 0 & 0 \\
\hline $\begin{array}{l}\text { Fohlen, et } \\
\mathrm{al}^{11}\end{array}$ & Pterional & 14 & $3(21)$ & $11(79)$ & $2(14)$ & $\begin{array}{l}\text { Hyperphagia (7); } \\
\text { panhypopituitarism } \\
\text { (14) }\end{array}$ \\
\hline $\begin{array}{l}\text { Fohlen, et } \\
\mathrm{al}^{11}\end{array}$ & Endoscopic s/p pterional & 7 & $3(43)$ & $1(14)$ & 0 & 0 \\
\hline $\begin{array}{l}\text { Jayalakshmi, } \\
\text { et } \mathrm{al}^{15}\end{array}$ & Pterional & 3 & $2(66)$ & 0 & 0 & 0 \\
\hline Drees, et al $\star^{9}$ & $\begin{array}{l}\text { TAIF, combined TAIF/Endoscopic, } \\
\text { Combined pterional or } \\
\text { FTOZ/endoscopic }\end{array}$ & 10 & 0 & Unknown & $2(29)$ & (57) \\
\hline Abla, et al ${ }^{1}$ & FTOZ & 10 & $4(40)$ & $4(40)$ & $\begin{array}{l}\text { VF cut (10); } \\
\text { Hemiparesis (10) }\end{array}$ & $\begin{array}{l}\text { DI (10); } \\
\text { Poikilothermia (10) }\end{array}$ \\
\hline $\begin{array}{l}\text { Palmini, et } \\
\mathrm{al}^{27}\end{array}$ & Pterional & 12 & $2(17)$ & $8(67)$ & $1(8)$ & 0 \\
\hline Regis, et al ${ }^{30}$ & SRS & 48 & $19(40)$ & $14(29)$ & 0 & 0 \\
\hline Abla, et $\mathrm{al}^{2}$ & SRS or SRS s/p microsurgery & 10 & $6(60)$ & $3(30)$ & 0 & 0 \\
\hline $\begin{array}{l}\text { Mathieu, et } \\
\mathrm{al}^{18}\end{array}$ & SRS & 9 & $4(44)$ & $1(11)$ & 0 & 0 \\
\hline $\begin{array}{l}\text { Wilfong, et } \\
\mathrm{al}^{43}\end{array}$ & LITT & 14 & $12(86)$ & 0 & 0 & 0 \\
\hline Du, et al ${ }^{10}$ & LITT & 7 & $6(86)$ & 0 & 0 & 0 \\
\hline $\mathrm{Xu}$, et al ${ }^{44}$ & LITT & 18 & $12(67)$ & $3(17)$ & STM (22) & $\begin{array}{l}\text { Hypothyroid (11); } \\
\text { weight gain (22) }\end{array}$ \\
\hline $\begin{array}{l}\text { Kameyama, } \\
\text { et } \mathrm{al}^{16}\end{array}$ & SRT & 100 & $71(71)$ & $15(15)$ & 0 & $\begin{array}{l}\text { Panhypopituitarism } \\
\text { (2); weight gain (7) }\end{array}$ \\
\hline
\end{tabular}

\section{Figures}



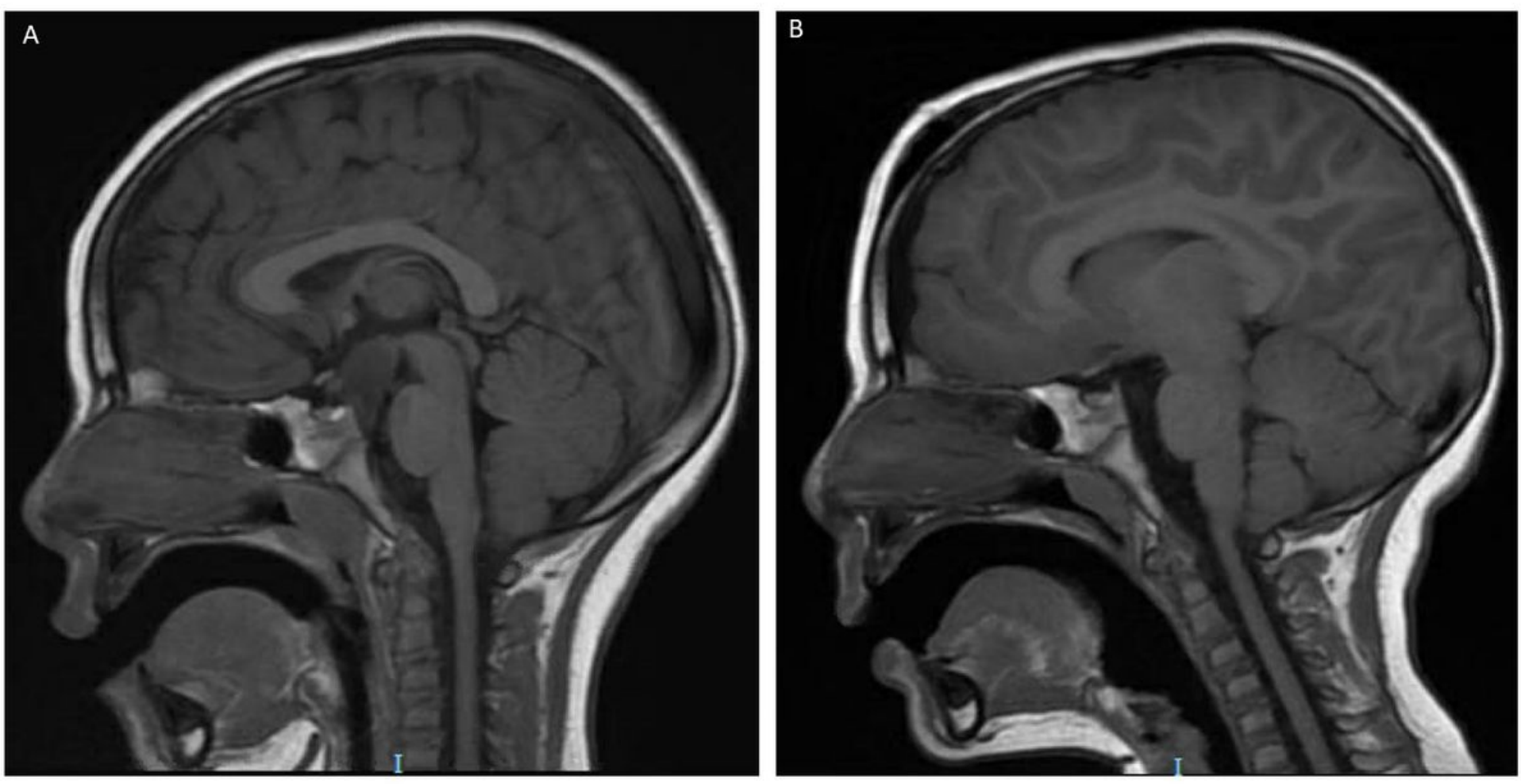

\section{Figure 1}

(A)Pre- and (B)Post-operative imaging for Patient 2 demonstrating a 18x20x20mm class $3 \mathrm{HH}$ involving the suprasellar and interpeduncular cisterns with intraventricular extension. Following endoscopic and FTOZ approaches, GTR was achieved resulting in seizure freedom.
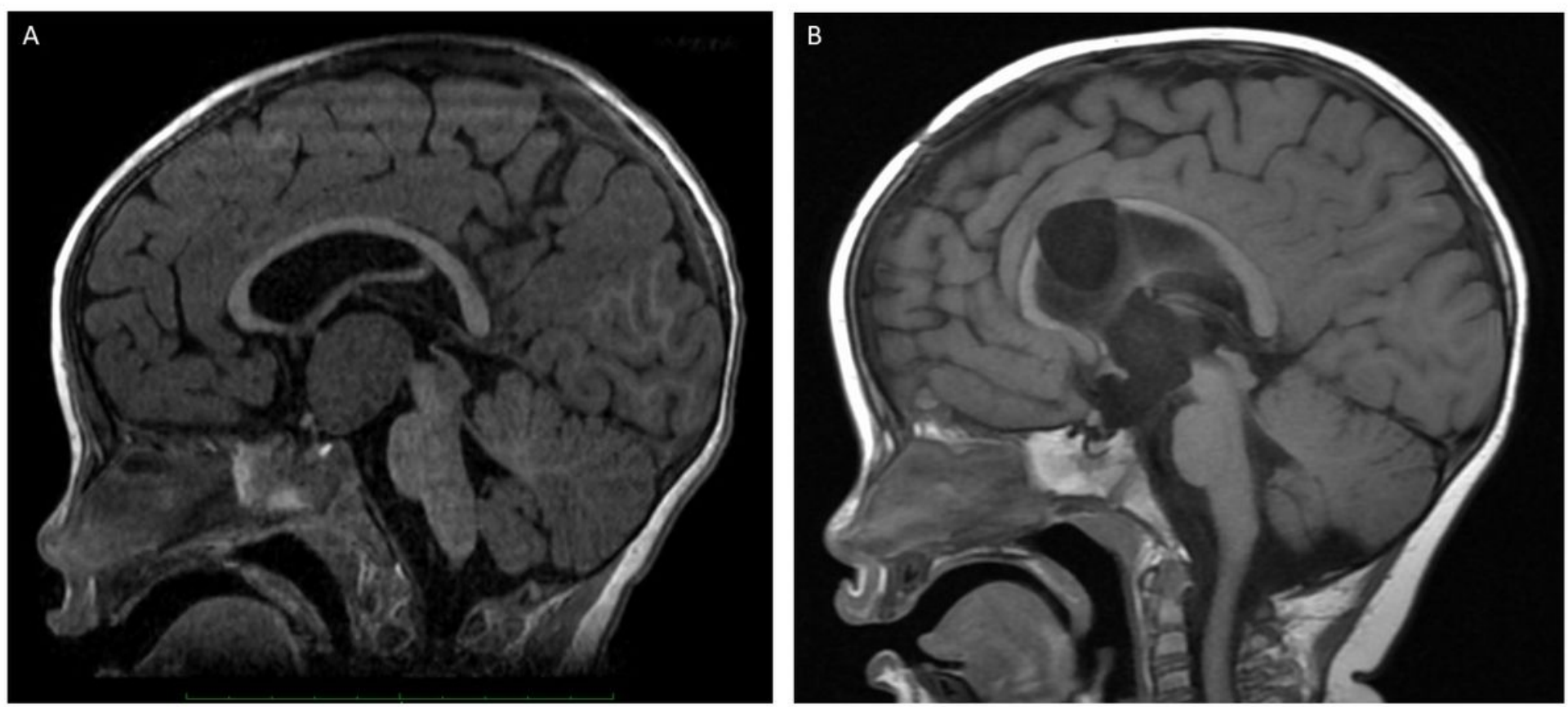

Figure 2 
(A)Pre- and (B)Post-operative imaging for Patient 3 demonstrating a 27x31x22mm class $3 \mathrm{HH}$ involving the suprasellar and interpeduncular cisterns with intraventricular extension. An estimated $99 \%$ resection was achieved following FTOZ, TAIF, and endoscopic resection resulting in seizure freedom.
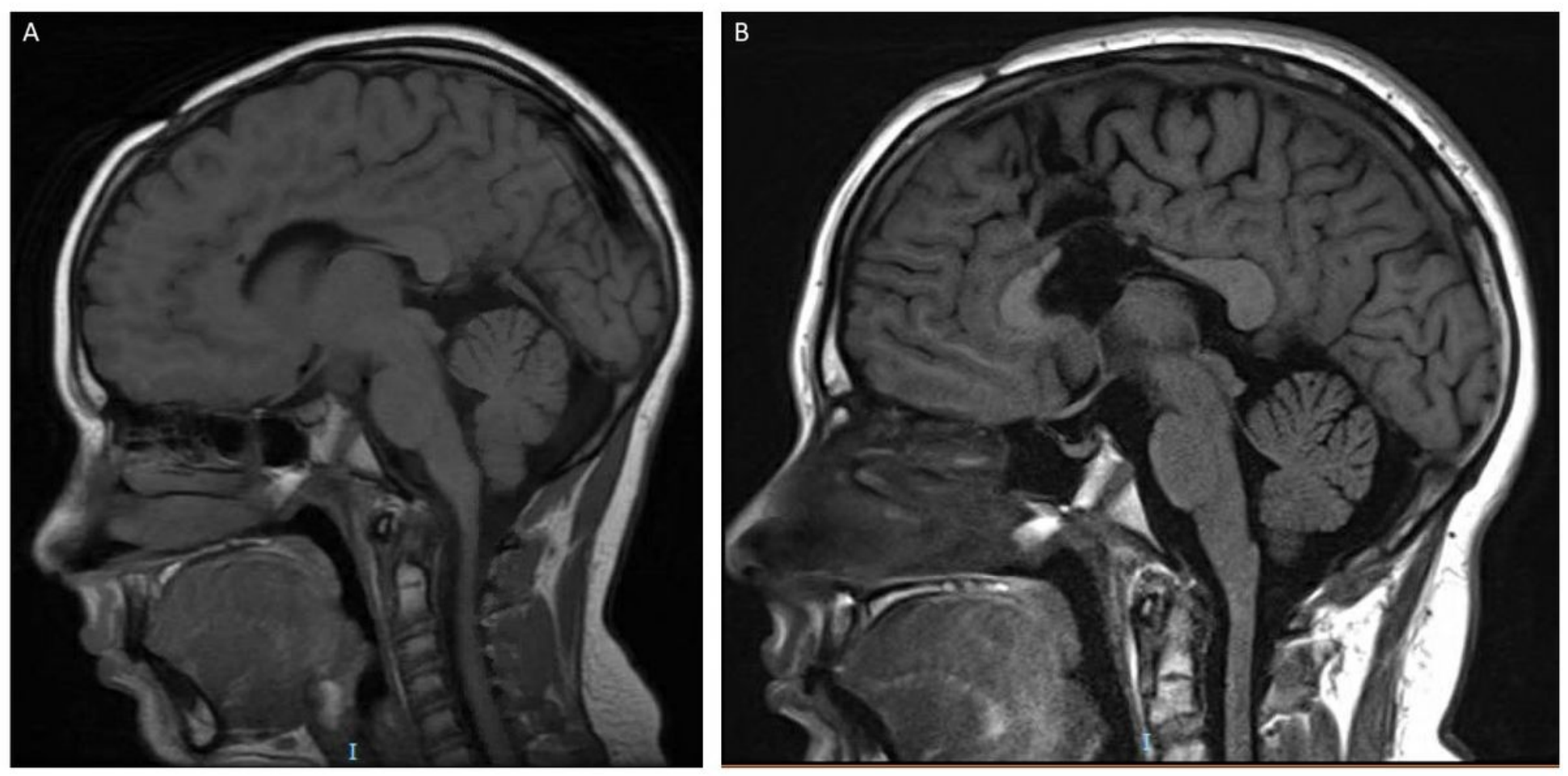

Figure 3

(A)Pre- and (B)Post-operative imaging for Patient 7 demonstrating a 13x14x10mm pedunculated HH following attempted endoscopic resection and LITT ablation. The patient underwent an FTOZ approach to achieve GTR and seizure freedom. 

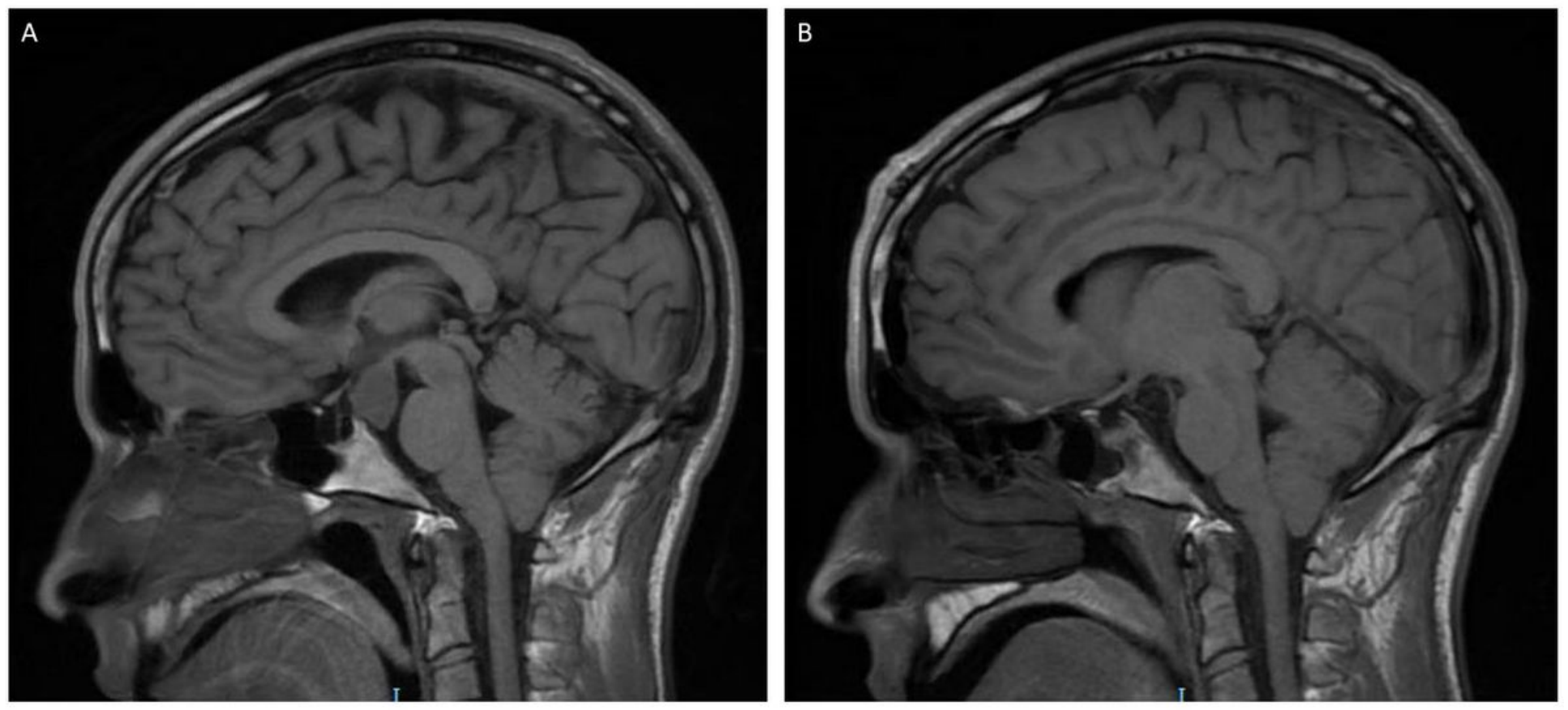

\section{Figure 4}

(A)Pre- and (B)Post-operative imaging for Patient 8 demonstrating a $22 \times 25 \times 16 \mathrm{~mm}$ pedunculated HH involving the interpeduncular and prepontine cisterns. The patient underwent an FTOZ approach to achieve GTR and seizure freedom. 